\title{
Considerações sobre elaboração de desenhos bidimensionais tangíveis no contexto da deficiência visual
}

\author{
Considerations regarding the elaboration of tangible two-dimensional \\ drawings in the context of visual impairment
}

Mari Ines Piekas

desenhos táteis, deficiência visual, acessibilidade

Considerando-se que em nossa sociedade muitas informações chegam apenas pelo sentido da visualidade, questões sobre representação de imagens em relevo têm motivado pesquisadores a procurarem entender a relação entre o signo visual e o signo tátil. Nesse sentido, o presente texto traz um recorte a partir de uma revisão da literatura que teve por objetivo identificar características norteadoras para elaboração de imagens táteis direcionadas a pessoas com deficiência visual, inicialmente aplicados em uma pesquisa acadêmica voltada ao ensino de desenho para crianças cegas, já concluída. A natureza exploratória da pesquisa possibilitou alcançar informações sobre o sistema sensorial háptico, leitura tátil e interpretação da imagem, recomendações e diretrizes para sua elaboração, tatilidade da linha, dimensões do desenho, imagens adaptadas para livros de literatura infantil, imagens por impressão 3D, dentre outros aspectos. Espera-se colaborar com outras investigações que vêm sendo realizadas com foco nas imagens táteis e elaboração de artefatos didáticos para pessoas com deficiência visual.

tactile drawings, visual impairment, accessibility

Considering that in our society a lot of information comes only through the sense of visuality, questions about the representation of relief images have motivated researchers to try to understand the relationship between the visual sign and the tactile sign. In this sense, this text brings an excerpt from a literature review that aimed to identify guiding characteristics for the development of tactile images aimed at people with visual impairment, initially applied in an academic research aimed at teaching drawing to blind children, already completed. The exploratory nature of the research made it possible to obtain information about the haptic sensory system, tactile reading and image interpretation, recommendations and guidelines for its elaboration, line tatility, drawing dimensions, images adapted for children's literature books, images by $3 D$ printing, among other aspects. It is expected to collaborate with other investigations that have been carried out with a focus on tactile images and the elaboration of didactic artifacts for people with visual impairments.

\section{Introdução}

A motivação para o desenvolvimento de soluções que busquem integrar, incluir e facilitar a vida de pessoas com necessidades educacionais especiais, bem como de todos os que convivem com elas, são compartilhadas principalmente no âmbito do design, da psicologia, das artes, da semiótica e da educação. Dentre essas necessidades estão aquelas encontradas na área da deficiência visual, para a qual muitos estudos se voltam, a fim de garantir a aquisição de

Anais do $10^{\circ} \mathrm{CIDI}$ e $10^{\circ} \mathrm{CONGIC}$

Kelli C.A.S. Smythe, Rafael de Castro Andrade (orgs.)

Sociedade Brasileira de Design da Informação - SBDI

Curitiba | Brasil | 2021
Proceedings of the $10^{\text {th }} \mathrm{CIDI}$ and $10^{\text {th }}$ CONGIC

Kelli C.A.S. Smythe, Rafael de Castro Andrade (orgs.)

Sociedade Brasileira de Design da Informação - SBDI Curitiba | Brazil | 2021 
conhecimentos e melhorar a qualidade de vida nos contextos educacional e sócio-culturais. Conforme sustenta Bonsiepe (2011, p. 89), o design nesse sentido, tem atuado cada vez mais na direção de "fomentar o metabolismo cognitivo, (...) facilitar a assimilação de informação", além do que, o perfil multidisciplinar do design procura potencializar a compreensão da mensagem (Dick et al, 2017). Ao se elaborar imagens, pratica-se uma interação e uma troca com o mundo que nos rodeia, seja tanto no âmbito da comunicação como da cultura e da arte, além do que para as pessoas cegas, representar ou reconhecer desenhos em relevo thes possibilita acessar um código universal usado e praticado pelas pessoas desde a infância (Cardeal, 2009). Desse modo, com o objetivo de entender melhor essas abordagens, pesquisou-se ${ }^{1}$ por meio de revisão bibliográfica, tipos de recomendações, diretrizes de leitura e elaboração de imagens táteis, bem como lacunas e desafios que existem, a fim de colaborar para estudos tão necessários e importantes nesse contexto. Procurou-se identificar algumas características norteadoras para elaboração de imagens táteis direcionadas a pessoas com deficiência visual, sendo este apenas um recorte da pesquisa realizada e que novos dados continuam a ser buscados e analisados.

\section{Leitura de imagens táteis}

Lima (2001) investigou o reconhecimento de figuras tangiveis a partir de um treinamento realizado por pessoas cegas totais. Além dos resultados positivos em relação ao reconhecimento de figuras e nomeação de desenhos, outras ocorrências foram evidenciadas, como a capacidade dos cegos de reconhecer hapticamente desenhos em relevo, que os cegos adultos utilizam estratégias diferentes das usadas pelas crianças na leitura das figuras, da importância de considerar a característica sequencial do tato e de disponibilizar materiais pedagógicos para os cegos.

Szubielska e Marek (2012) destacam que, mesmo que haja a capacidade de perceber e reconhecer linhas em relevo e texturas, a compreensão de representações bidimensionais de objetos e diagramas bem como a relação espacial entre eles não ocorre tão facilmente. Sobre isso, na opinião de Lima (2001) a partir de Heller $(1989,1991)$, a compreensão está associada ao tempo de observação háptica dispensado no exercício da leitura tátil. Para Hatwell (1995 apud Lima, 2001) muitos desses resultados estão muitas vezes associados à falta de material adequado e não aos aspectos cognitivos de pessoas com deficiência visual. Já as reflexões de Correa Silva (2011, p. 89) a partir de Millar (1975) complementam o estudo de Lima (2001) afirmando que deve ser levado em conta o estímulo que é proporcionado pelas "[...] características formais e estruturais principais que ajudam a inferir o objeto examinado [...]”, já que muitas vezes o desenho não fornece informações suficientes em relação ao objeto representado. Para Lima $(2001,2004)$, é pertinente ressaltar a importância da simplicidade no desenho, como também de se estar atento aos elementos distratores, que podem levar a uma leitura errônea da forma e sobrecarregar a memória semântica. Este autor afirma que deve ser

\footnotetext{
${ }^{1}$ Este artigo é um recorte de uma pesquisa acadêmica de Piekas (2017)
} 
considerado quais elementos devem e os que não devem ser eliminados do desenho, já que isso pode também comprometer a informação que se quer transmitir. Os elementos distratores, conforme Lima aponta, podem ser relacionados ao que Frascara (2004 apud Prime al, 2019) denominam de ruídos no âmbito da informação. Para além da atenção aos elementos que devem fazer parte do desenho, outro aspecto que merece destaque é a mediação de outra pessoa durante a leitura tátil do objeto tridimensional e da imagem bidimensional tangível. Nesse sentido, Lima (2001) corrobora Eriksson (1999), Duarte (2011) e Da Silva, Ulbricht e Padovani (2015), autores que discutem essa característica no ambiente de aprendizagem.

Outro importante teórico que estuda a imagem e deficiência visual é Kennedy (1993), autor que identificou que a pessoa cega compreende que a linha de contorno do desenho representa a linha de contorno do objeto tridimensional examinado pelos dedos. Dentre seus enfoques estão a leitura tátil e a realização de desenhos de objetos do cotidiano, de sólidos geométricos, exercícios de orientação espacial e estudo das propriedades da superfície por meio de tipos de linhas.

Eriksson (1999) compartilha conclusões semelhantes reafirmando que não basta transferir uma imagem visual para uma imagem em relevo, e reforça que a forma deve ser clara e simples, com componentes destacados e facilmente identificados. A partir de suas investigações, Eriksson atribui à forma como sendo a principal característica observada na distinção de um objeto, sendo o tamanho, o material e a cor, elementos secundários nessa observação. Nesse mesmo enfoque, para Bardisa (1992), o estímulo à leitura tátil do objeto e do desenho deve ser constante para que esta se torne cada vez mais refinada, inclusive aprimorando a psicomotricidade da pessoa cega.

Para Szubielska et al. (2016), reconhecer e interpretar desenhos de objetos é de grande importância para as pessoas com deficiência visual, pois muitos detalhes e características de determinados objetos não são possíveis de serem compreendidos verbalmente. Para os autores, grande parte da competência para leitura de gráficos e desenhos em relevo provém do aprendizado e da prática com estes materiais, além das habilidades pessoais e imaginação espacial.

Outro assunto que merece atenção é a falta de padronização das imagens nos materiais gráficos (Więckowska, 2003; Duarte e Cardeal, 2008; Cardeal, 2011). Para Cardeal (2011) as imagens dos livros denominados inclusivos foram na maioria concebidas de modo aleatório, transpondo-se para linha tátil a imagem visual, o que muitas vezes torna-se ilegível pela criança cega. Nuernberg (2010, p. 136) compartilha do pensamento de Cardeal dizendo que "Transformar imagens que possuem perspectiva e representam objetos em três dimensões em relevos de pontos acaba limitando a condição de acesso, esforço que deveria garantir a plena acessibilidade metodológica e conceitual." Desse modo, deve-se ter atenção às convenções aprendidas na cultura visual e que muitas vezes a pessoa cega não consegue acessar.

A experiência de leitura e elaboração de desenhos realizados por jovens com deficiência visual com foco na comunicação é apresentada por Darras e Valente (2013), autores que se utilizaram das convenções da cultura visual, verificando como se daria a tradução desses 
aspectos por meio da fala e do traçado, a partir da qual concluíram que a privação de informação sobre desenhos prejudica a leitura e a compreensão das imagens bidimensionais. Na observação de Darras e Valente (2013, p. 88), os traços e ângulos percebidos tatilmente eram compreendidos apenas como "signos geométricos", e não como "signos figurativos" mais complexos, além do que, certos elementos gráficos, próprios da cultura visual, não fizeram sentido para esses jovens com deficiência. Para os autores é importante compreender que não basta transpor os padrões da cultura visual para o público deficiente visual, deve-se levar em consideração o seu modo de percepção, interação e de como assimila o seu entorno, a fim de favorecer o seu acesso ao mundo das imagens..

Adam (2015) realizou pesquisa de revisão bibliográfica no âmbito de observar o potencial informacional da sintaxe gráfica, com enfoque na acessibilidade das pessoas com deficiência visual. Além das diretrizes, a autora elaborou um quadro analítico que serviu para identificar o que vem sendo utilizado em relação às características dessa sintaxe a partir de imagens em relevo para objetos de aprendizagem (Adam, 2015, p. 171-184). O quadro abaixo mostra algumas das figuras utilizadas para análise.

Figura 1: Detalhe da amostra a partir do Repositório de imagens TGIL. Fonte: Adam (2015, p. 173)

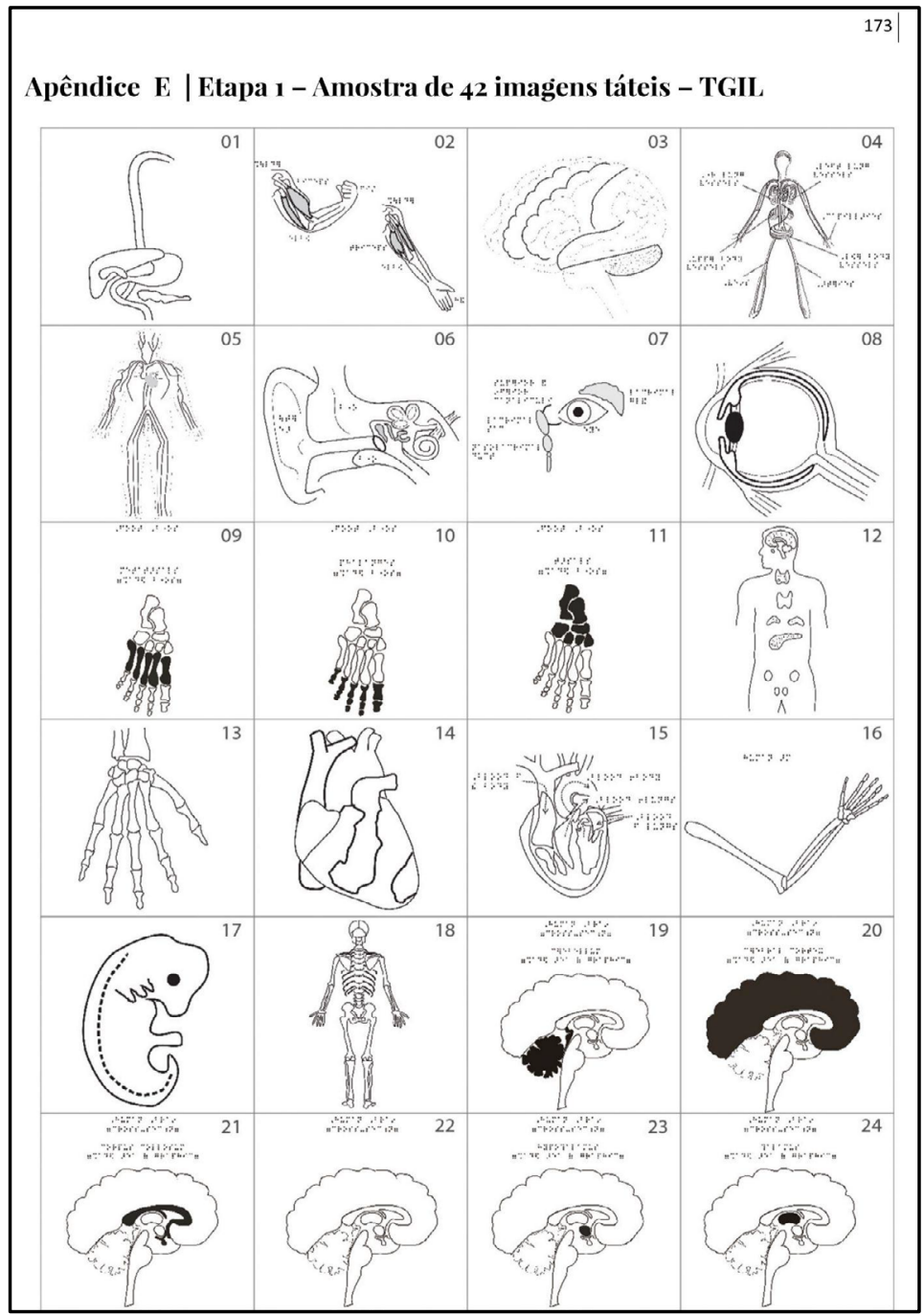


Outros dados importantes se referem à simplicidade da forma, à orientação, à escala e à proporção, fatores fundamentais para facilitar a interpretação da imagem (Adam, 2015). Já na análise do repertório de imagens TGIL, a partir de desenvolvedores de imagens e educadores a autora pode evidenciar alguns itens que podem comprometer a compreensão do desenho, dentre os quais:

a. a sobreposição de elementos;

b. a pouca diferenciação entre os tipos de linhas;

c. a inexistência de texto explicativo.

Por outro lado, identificou variáveis gráficas em diferentes graus de manifestações, como por exemplo, a presença da linha, contraste entre figura-fundo, além de textura e preenchimento (Adam , 2015, p. 149). Dentre os aspectos observados, a autora aponta para a necessidade de um conhecimento sobre a utilização da sintaxe gráfica na elaboração e adaptação de imagens para deficientes visuais.

Com os avanços tecnológicos outros tipos de materiais passaram a ser utilizados na elaboração de imagens para pessoas com deficiência visual, a exemplo da impressão 3D ou prototipagem rápida. Para Sobral et al. (2015), muitos artefatos têm sido desenvolvidos e a impressão 3D demonstra ter um grande potencial tanto em atividades comunicacionais quanto educacionais de pessoas com deficiência visual. Nesse mesmo sentido, a pesquisa de Sanches (2018) se direcionou no sentido de entender a importância da impressão 3D na elaboração de objetos de aprendizagem para o ensino, a partir dos princípios e recomendações de acessibilidade. O objetivo da sua investigação foi o de propor um modelo de tradução de imagens estáticas bidimensionais, existentes nesses objetos e em imagens táteis tridimensionais.

A seguir serão listados alguns aspectos e recomendações evidenciados pelos autores estudados. É válido ressaltar que este levantamento de dados não se esgota neste artigo, pelo contrário, é um desejo de aproximação de uma área que deve continuar com estudos cada vez mais aprofundados.

\section{Aspectos e recomendações para elaboração de imagens táteis}

A partir de uma análise de 20 figuras em relevo encontradas em livros didáticos, Correa Silva (2011) destaca que muitas representações não são compreendidas na sua plenitude proporcionando somente sensações táteis. A autora aponta como causa dessa situação o senso comum de que soluções que funcionam para visão podem funcionar para o tato onde se faz a transposição para relevo das imagens à tinta. Por outro lado ela identifica alguns aspectos positivos nas imagens analisadas, dentre os quais: 
a. contornos precisos e formas nítidas;

b. as composições são simplificadas e respeita-se certa distância entre as figuras;

c. usa-se a cor (para pessoas com baixa visão);

d. algumas lâminas utilizam a escrita em braille;

e. não são representadas as sombras, facilitando a leitura da imagem;

f. usa-se linhas orgânicas para objetos da natureza e linhas retas para objetos tecnológicos;

g. há diferentes níveis de iconicidade, com imagens mais ou menos detalhadas;

h. tratamento da superfície do desenho com texturas semelhantes com o objeto e o uso de diferentes materiais para diferenciar as representações.

A seguir alguns exemplos de imagens com aspectos negativos a partir da análise de Correa Silva (2011):

Tabela 1: Exemplos de aspectos negativos observados por Correa Silva.

Fonte: Correa Silva (2011, p. 141-143).

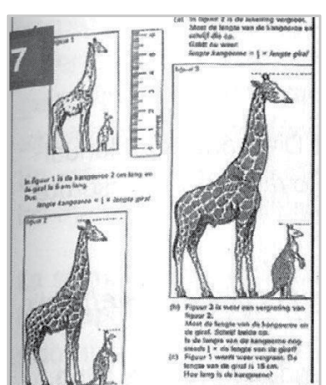

Existem mais características de semelhança da imagem com o objeto do que abstração dos elementos
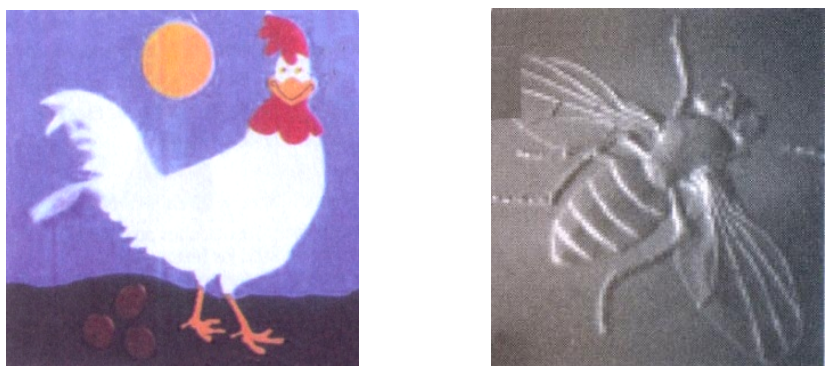

Não há o uso da perspectiva, entretanto, utiliza-se o escorço (bico do galo)
As vistas são na maioria frontais ou aéreas (vista superior)

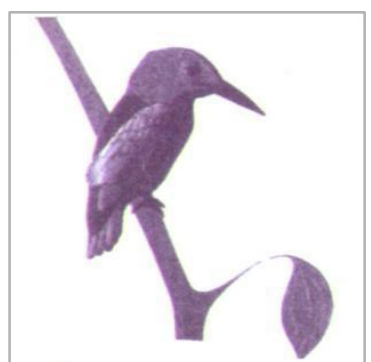

Há sobreposição de figuras

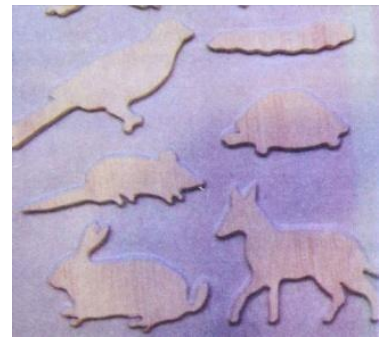

Muitas figuras mostram apenas a silhueta do objeto, sem detalhes internos

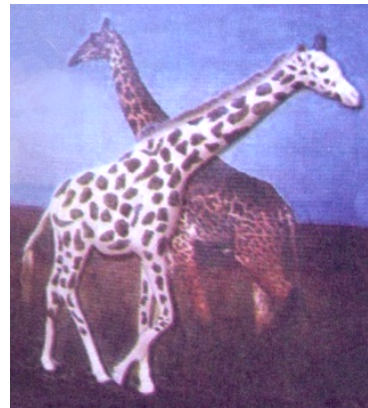

Em função de cruzamento de linhas, algumas formas ficam estranhas

De maneira semelhante Więckowska (2003) faz recomendações em relação às características da imagem tátil: 
a. simplicidade (omitir detalhes desnecessários);

b. atratividade (ser agradável ao toque);

c. a forma da figura deve estar relacionada à forma do objeto;

d. coerência (por exemplo, usar marcações, planos e eixos de maneira semelhante nos desenhos);

e. usabilidade (não ornamentar o material a ponto de prejudicar a leitura tátil e usar figuras que são familiares à criança, pois o objetivo do desenho também pode ser de entretenimento);

f. durabilidade (o desenho em relevo não deve se deteriorar com facilidade pelo manuseio do dia a dia);

g. as imagens devem ser facilmente encontradas na página, de preferência estarem centralizadas;

h. as proporções da figura devem estar de acordo com a realidade;

i. a inserção de mais detalhes no desenho deverá estar de acordo com as habilidades mentais da criança;

j. aplicar regras semelhantes na elaboração de desenhos em todas as áreas de ensino;

k. diferenciar objetos utilizando texturas diferentes em uma mesma composição;

I. fechar a linha de contorno da figura;

$\mathrm{m}$. distinguir as suas propriedades quando houver mais de um elemento da composição do modo a um elemento não obstrua os outros (Więckowska, 2003).

Tabela 2: Características de imagens táteis. Fontes indicadas nas figuras.

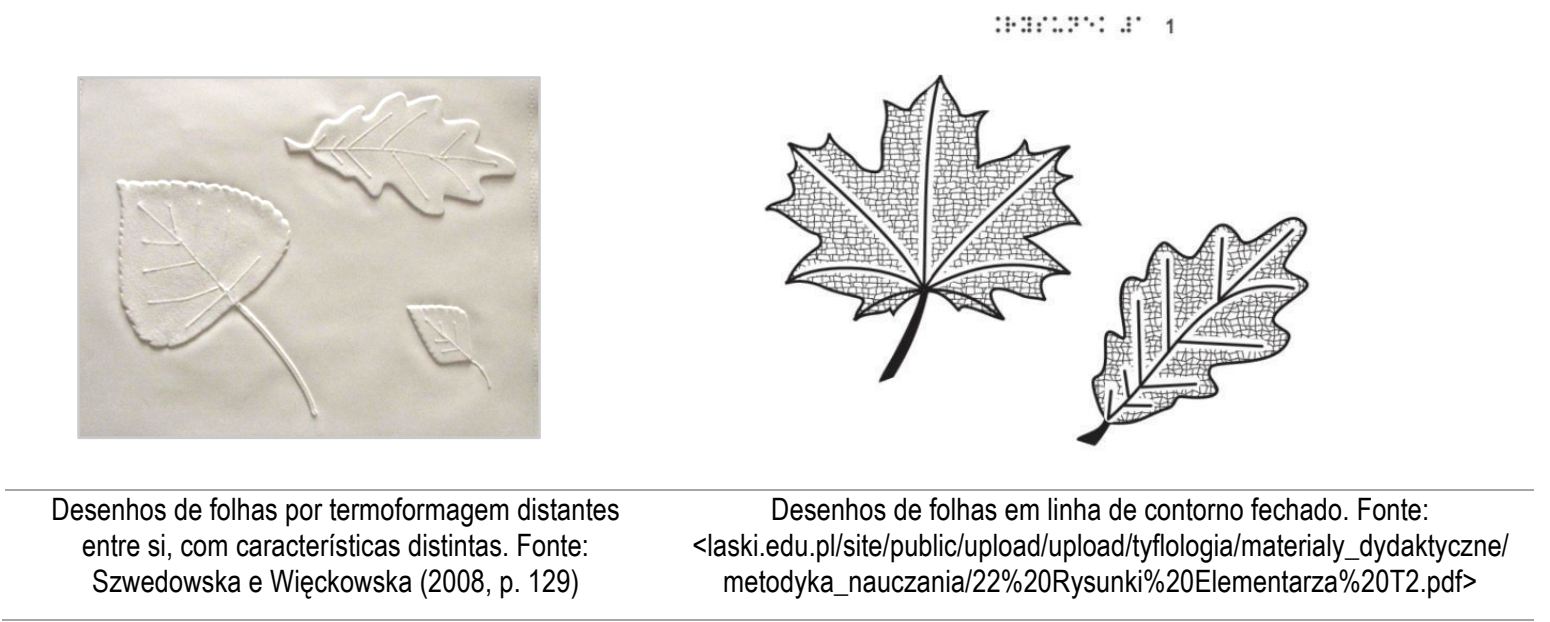

Para Ripley (2009), objetos, pessoas e animais representados em livros de literatura infantil, por exemplo, são mais facilmente identificados se mostrados em sua totalidade. O modo como é apresentada a imagem na página também tem grande relevância, como nos exemplos da própria autora, a seguir: 
Tabela 3: Recomendações de usos de imagens em livros de literatura infantil para crianças cegas. Fonte: Ripley (2009, p. 61, 66 e 67)

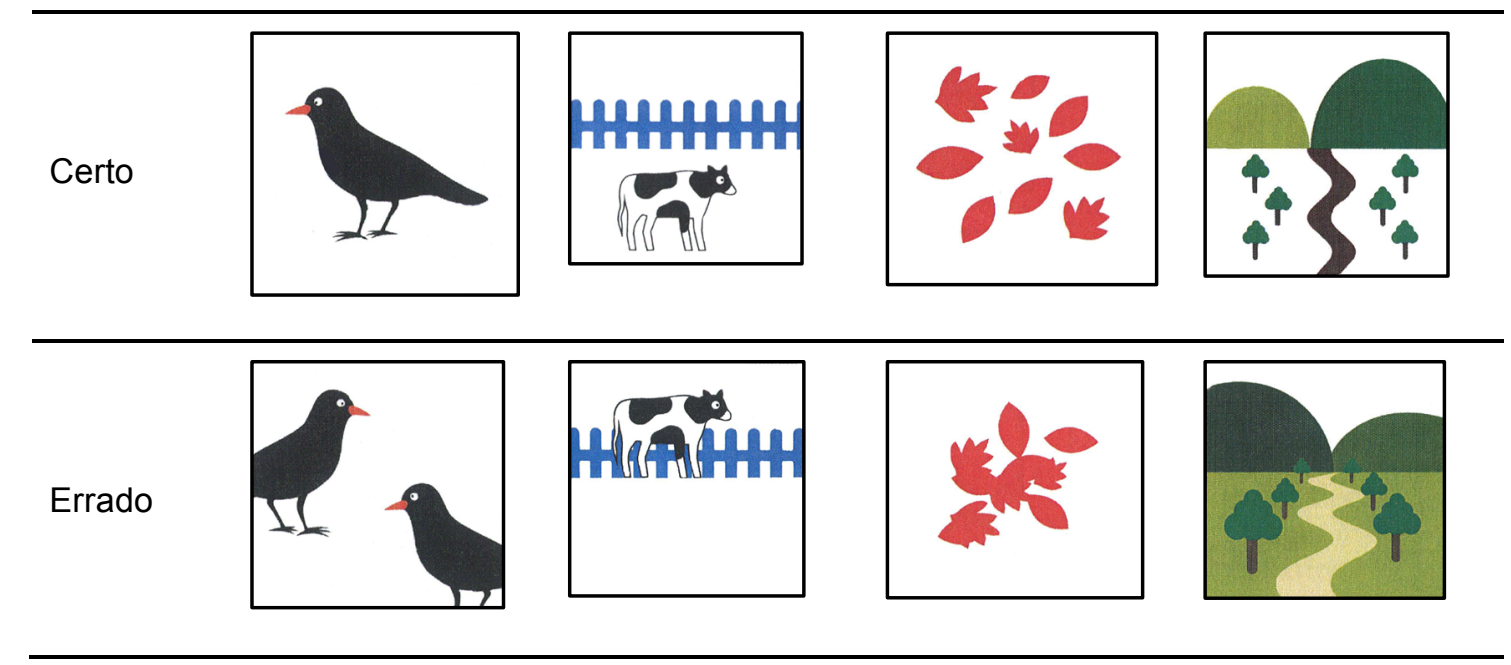

Ainda nesse contexto, Cardeal (2011) selecionou mais de 50 ilustrações em livros de literatura infantil, solicitando que as crianças cegas as identificassem. Desse estudo chegou às seguintes recomendações:
a. a linha de contorno deve ser definida (ou fechada);
b. a forma deve ser esquemática;
c. repetir a mesma forma (redundância);
d. elaborar formas limpas, simplificadas e sem detalhes.

Tabela 4: Aspectos positivos do desenho tátil. Fonte: Cardeal (2011, p. 93, 122 e 124).

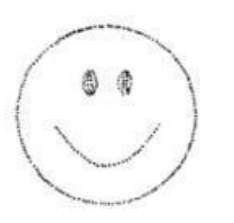

A linha de contorno da ilustração deve ser definida (ou fechada)

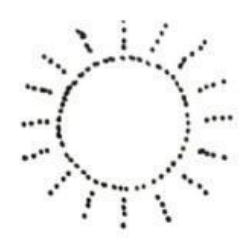

A forma deve ser esquemática

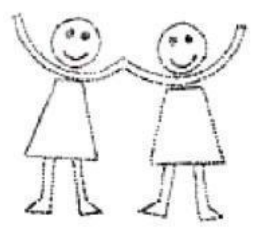

Repetir a mesma forma (redundância)

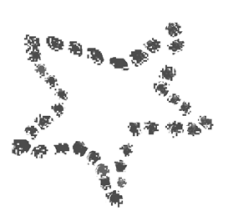

Elaborar formas limpas, simplificadas e sem detalhes

Cardeal também destaca alguns aspectos negativos em relação aos desenhos táteis, e que podem ser vistos na sequência: 
Tabela 5: Aspectos negativos do desenho tátil. Fonte: Cardeal (2011).

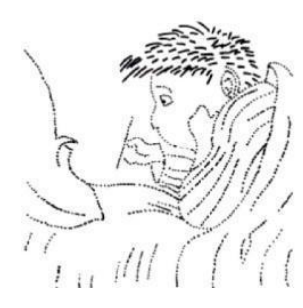

A figura ter o contorno aberto e não ser esquemática

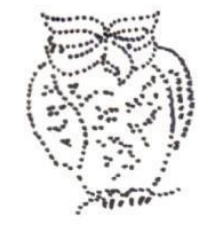

Ter formas complexas

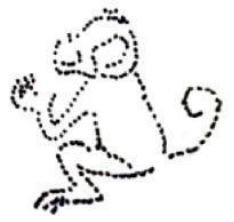

Deixar o contorno irregular da

linha com espacejamento variado entre os pontos

Do mesmo modo, Claudet (2009) também apresenta recomendações de como elaborar imagens em livros de literatura multissensoriais. Dentre suas orientações estão:

a. elaborar ilustrações que sejam pertinentes, claras e simplificadas;

b. não inserir muitos detalhes sobre a página;

c. utilizar diferentes texturas para diferentes partes de um objeto;

d. evitar que os desenhos fiquem sobrepostos;

e. manter a proporção;

f. evitar a perspectiva;

g. mostrar animais de perfil e pessoas de frente;

h. manter as mesmas características do personagem em todo o livro.

Em sua pesquisa sobre imagens em impressão 3D, Sanches (2018, p. 59) apresenta um quadro em torno de 37 recomendações distribuídas em quatro categorias, sendo elas a criação de imagens táteis, a composição da imagem tátil, a simplificação, aspectos físicos da imagem e usuários. Algumas das recomendações mais recorrentes são apresentadas a seguir:

a. evitar uso apenas de formas geométricas básicas;

b. combinar elementos de ponto, linha e textura com informações tridimensionais (volume);

c. utilizar formas identificáveis e familiares para símbolos, cada símbolo diferente e de fácil identificação;

d. definir leiaute para o conjunto de imagens táteis;

e. manter a mesma escala para o conjunto de imagens táteis, além de manter consistência nos elementos;

f. simplificar elementos para compreensão tátil, porém manter detalhes essenciais; 
g. bordas devem ser eliminadas a não ser pela borda de referência e de limites;

h. levar em consideração limitações técnicas da impressora 3D, recursos financeiros, portabilidade e possibilidade de impressão em outros lugares;

i. utilizar pós-processamento para que a impressão não fique áspera ou muito lisa.

Abaixo um exemplo de imagem em impressão 3D utilizada por Sanches (2018, p. 105)

Figura 2: Mapa de rotas tátil em impressão 3D. Fonte: Sanches, 2018, p. 105.

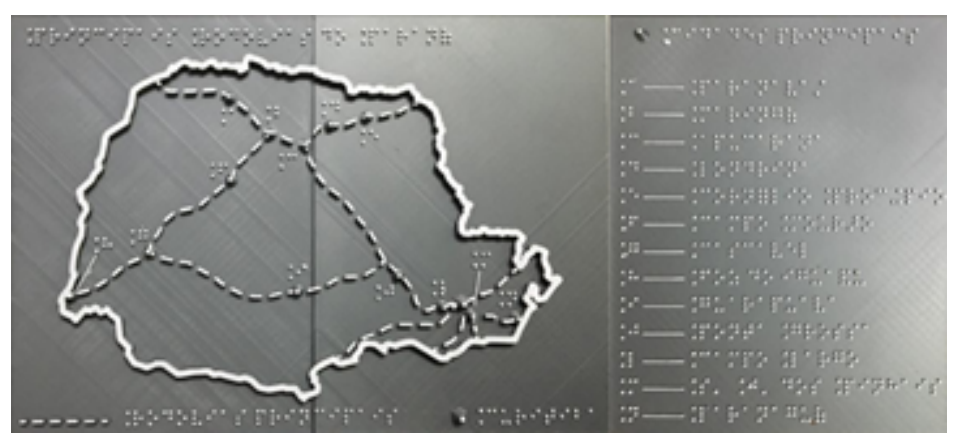

\section{Possíveis caminhos para a elaboração de desenhos táteis}

Esse breve levantamento de informações a partir da revisão bibliográfica possibilitou extrair opiniões que se assemelham entre si, no que diz respeito às características norteadoras para elaboração de imagens táteis. Vale ressaltar a opinião dos autores, ao afirmarem que essa é uma área de pesquisa que precisa de avanços e que os estudos aqui apresentados refletem apenas uma pequena parte de suas investigações. Para tanto, segue um resumo de algumas recomendações abordados neste artigo:

a. não transferir a imagem visual para imagem tátil de modo aleatório ou como uma cópia, sem estudá-la previamente;

b. observar o tamanho do desenho para que este transmita uma informação global do objeto;

c. observar as distâncias entre linhas e formas;

d. a imagem deve ter boa tangibilidade;

e. respeitar escalas e proporções de acordo com a realidade;

f. observar quais são as características essenciais do objeto que merecem ser decodificadas para imagem;

g. não abstrair detalhes que sejam fundamentais para a identificação do objeto bidimensional;

h. simplificar e esquematizar o desenho;

i. representar no desenho a textura característica do objeto; 
j. usar simetria;

k. inserir um marco de orientação na página do desenho;

I. deixar os contornos fechados na figura;

m. considerar a importância da mediação, principalmente no início da aprendizagem da leitura tátil de objetos e respectivos desenhos;

n. padronizar os desenhos para que sejam utilizados em outras áreas de ensino;

o. destacar a figura do fundo e procurar deixá-lo liso, sem interferências gráficas desnecessárias;

p. evitar o uso da perspectiva;

q. evitar sobrepor desenhos para não gerar uma outra forma desconhecida ao tato;

r. manter a redundância das formas, ou seja, repetir as características comuns dos desenhos;

s. treinar a leitura tátil de desenhos a fim de promover maior reconhecimento e nomeação de figuras;

t. manter a mesma escala para o conjunto de imagens táteis, além de manter consistência nos elementos;

u. promover uma construção da linguagem de desenho por meio da sua prática.

Observou-se, também, que algumas opiniões estão voltadas para a elaboração de uma biblioteca de representações gráficas táteis (Marek, 2009), de códigos tátil-visuais (Duarte, 2011), ou mesmo de um alfabeto tátil (Correa Silva, 2011), com o objetivo de ampliar a possibilidade de uso, informação e comunicação por meio de desenhos.

Vale ressaltar também que, segundo alguns autores (Duarte, 2011; Bardisa, 1992; Lima, 2001; Cardeal, 2011), os exercícios de desenho e a prática motora para o traçado colaboram para a memorização da forma, bem como para a capacidade de leitura tátil, que está relacionada à noção de conceitos espaciais e treinamento com figuras bidimensionais tangíveis.

\section{Considerações finais}

O presente texto procurou evidenciar recomendações acerca da elaboração de imagens bidimensionais tangíveis que são elaboradas e direcionadas às pessoas com deficiência visual. Por meio da revisão da literatura realizada em livros, artigos, teses e dissertações, foi possível contextualizar as questões pertinentes à pesquisa em questão, além de fomentar discussões com os pares em grupos de pesquisa. Esse método de pesquisa é parte essencial de um trabalho científico, pois por meio dele é possível contextualizar o objeto pesquisado, além de fomentar novas buscas teóricas.

Observou-se que os caminhos trilhados até aqui indicam a necessidade de se aprofundar, tendo-se em mente que é uma área de pesquisa multidisciplinar, cujo intuito é favorecer a formação e inclusão de pessoas com essa deficiência de um modo mais pleno e significativo. Com isso, a atuação de vários profissionais e da comunidade envolvida na elaboração desses 
artefatos educativos torna-se fundamental, a fim de colaborar para o processo da educação, acesso à cultura e autonomia das pessoas com deficiência visual.

\section{Referências}

Adam, D. L. (2015). Premissas de criação de imagens em relevo em objetos de aprendizagem para cegos. [Dissertação de Mestrado, Universidade Federal do Paraná]. https://acervodigital.ufpr.br/bitstream/handle/1884/37964/R\%20-\%20D\%20\%20DOMINIQUE\%20LEITE\%20ADAM.pdf?sequence=3\&isAllowed=y

Barraga, N. (1978). Disminuidos visuales y aprendizaje. Madrid: ONCE.

Bonsiepe, G. (2011). Design, cultura e sociedade. Blucher.

Cardeal, M. (2011) Metáforas visuais - redundâncias táteis. In: Duarte, Maria Lúcia B.; Piekas, M. I. (Org.). Desenho infantil em pesquisa: imagens visuais e táteis. Insight. Apoio Capes.

Claudet, P. (2009) The typhlo and tactus guide to children' books. Talant: Les Doigts Qui Revent.

Claudet, P. Guidelines for making tactile books. 2017. (pp. 20). http://www.tactus.org/guidelines.html

Correa Silva, M. P. (2011). Imágenes que podemos tocar. Santiago: Ediciones Universidad Tecnológica Metropolitana.

Darras, B., \& Valente, D. (2013). Communication graphique et cécité: étude sémiotique pragmatique de la production et l'interprétation des signes figuratifs produits par des jeunes non- voyants. MEI - Médiation et Information, Revue Internationale de Communication, Handicap \& Communication, 36. http://www.mei-info.com/wpcontent/uploads/2013/12/MEI36-79-94-Communication-graphique-et-cecite.pdf

Da Silva, F. C. P., Ulbricht, V. R., Padovani, S. (2015). A percepção tátil de variáveis gráficas no reconhecimento de objetos tridimensionais para cegos congênitos. Blucher Design Proceedings, v. 2, n. 2, (pp. 410-423).

Dick, M. E., Gonçalves, B. S., \& Vitorino, E. V. (2017). Design da informação e competência em informação: relações possíveis | Information design and information literacy: possible relationships. InfoDesign - Revista Brasileira de Design Da Informação, 14(1), (pp. 1-13). https://doi.org/10.51358/id.v14i1.500

Duarte, M. L. B. (2011). Desenho infantil e seu ensino a crianças cegas. Razões e método. Curitiba: Insight. Apoio Capes.

Duarte, M. L. B. \& Cardeal, M. (2008). É bonito, mas será arte? https://www.yumpu.com/pt/document/view/12577112/e-bonito-mas-sera-arte-ceart-udesc

Eriksson, Y. (1999). How to make tactile pictures understandable to the blind reader. In: IFLA COUNCIL AND GENERAL CONFERENCE, 65, Bangkok, Thailand. https://archive.ifla.org/IV/ifla65/65ye-e.htm

Heller, M. A.\& Schiff, W. (1991) The psychology of touch. New Jersey: Lawrence Erlbaum Associates, 1991.

Heller Morton. (2006). Picture perception and spatial cognition in visually impaired people. In: Heller, M. A.; Ballesteros, S. Touch and blindness. Psychology and Neuroscience. New Jersey: Lawrence Erlbaum Associates. 
Kennedy, John M. (1993). Drawing and the blind: pictures to touch. London: Yale University Press.

Lima, Francisco J. de. (2001). O efeito do treino com desenhos em relevo no reconhecimento háptico de figuras bidimensionais tangíveis. Tese (Doutorado em Psicologia) - Faculdade de Filosofia, Ciências e Letras de Ribeirão Preto, Universidade de São Paulo, Ribeirão Preto.

Lima, Francisco J. de. (2004). Ensinando reconhecer desenhos pelo tato: o efeito do treino no desempenho de pessoas cegas na nomeação de figuras examinadas hapticamente. pucpr.br/eventos/educere/educere2004/anaisEvento/Documentos/MR/MR-CI0180.pdf

Marek, Boguslaw. (2009). Filling the gap: from tactile pictures books to tactile graphics. In: Claudet, Phillipe. The typhlo and tactus guide to children' books. Talant: Les Doigts Qui Revent.

Millar, Suzanne. (1975) Spatial memory by blind and sighted children. British Journal of Psychology, n. 66, p. 449-459.

Nuernberg, Adriano H. (2010). Ilustrações táteis bidimensionais em livros infantis: considerações acerca de sua construção no contexto da educação de crianças com deficiência visual. https://periodicos.ufsm.br/educacaoespecial/article/view/1438

Piekas, Mari Ines. (2017). Elementos da linguagem visual e ensino de desenho para crianças cegas. [Tese de doutorado]. Centro de Artes. Universidade do Estado de Santa Catarina.

Primo, Lane; Ulbricht, Vania Ribas \& Fadel, Luciane Maria. (2019). Design da informação em conteúdos educacionais para experiência de aprendizagem inclusiva. (pp. 881-890) . In: Anais do $9^{\circ} \mathrm{CIDI}$ | Congresso Internacional de Design da Informação, edição 2019 e do $9^{\circ}$ CONGIC | Congresso Nacional de Iniciação Científica em Design da Informação. São Paulo: Blucher. ISSN 2318-6968, DOI 10.5151/9cidi-congic-2.0169

Ripley, Marion. (2009). Creating a loans collection of tactile books for young children with a visual impairement. In: Claudet, Phillipe. The typhlo and tactus guide to children' books. Talant: Les Doigts Qui Revent.

Sanches, Emilia Christie Picelli. (2018). Modelo de tradução para acessibilidade de imagens estáticas de objetos de aprendizagem através de impressão tridimensional. Dissertação (Mestrado) - Universidade Federal do Paraná. Setor de Artes, Comunicação e Design, Programa de Pós-Graduação em Design. Curitiba, 193 f. https://acervodigital.ufpr.br/bitstream/handle/1884/37964/R\%20-\%20D\%20\%20DOMINIQUE\%20LEITE\%20ADAM.pdf?sequence=3\&isAllowed=y

Sobral, João Eduardo Chagas; Cavalcanti, Anna Luiza Moraes de Sá \& Everling, Marli Teresinha. (2015). Ver com as Mãos': A Tecnologia 3d Como Recurso Educativo Para Pessoas Cegas. Anais do $15^{\circ}$ Ergodesign \& Usihc [= Blucher Design Proceedings, vol. 2, num. 1]. São Paulo: Blucher, (pp. 1327-1335). http://pdf.blucher.com.br.s3-sa-east1.amazonaws.com/designproceedings/15ergodesign/114-U123.pdf

Szubielska, Magdalena; Marek, Bob. (2012) Comprehension of tactile graphics by school-aged children with severe visual impairment: the role of tactile perception and spatial imagery. In: European Conference on Developmental Psychology, 15, 23-27, Bergen, Norway. Merimond International Proceedings... Bologna: Medimond Publisher. 
Szubielska, Magdalena; Niestorowicz, Ewa; Marek, Bogusław. (2016). Jak rysują osoby, które nigdy nie widziały? Badania niewidomych uczniów. Roczniki Psychologiczne/Annals of Psychology, v. 19, n. 4, p. 659-680.

Valente, Dannyelle; Bara, Florence; Gentaz, Edouard. (2018). Un guide pour concevoir des livres multisensoriels accessibles à tous avec la méthode du design participatif. Exemple d'un livre conçu avec les enfants en situation de handicap visuel. (hal02098388/.https://www.academia.edu/42424137/UN_GUIDE_POUR_CONCEVOIR_DES_L IVRES_MULTISENSORIELS_ACCESSIBLES_\%C3\%80_TOUS_AVEC_LA_M\%C3\%89TH ODE_DU_DESIGN_PARTICIPATIF_Exemple_dun_livre_con\%C3\%A7u_avec_les_enfants_ en_situation_de_handicap_visuel

Więckowska, S. Elzbieta. (2003). Rysunek w nauczaniu początkowym dzieci niewidomych.

Referat. In: Nowoczesne Techniki Kształcenia Niewidomych i Słabowidzących. Europejska Konferencja w Owińskach 25-04-2003. Wyd. Oficyna Edukacyjna Wydawnictwa EMPI. Poznań. http://www.rysunki.pzn.org.pl/wiecko3.pdf

\section{Sobre a autora}

Mari Ines Piekas, Dra., UFPR (Curitiba - PR), Brasil <maripiekas@gmail.com> 